\title{
Article \\ Effect of Aggregate Size on Recycled Aggregate Concrete under Equivalent Mortar Volume Mix Design
}

\author{
Haneol Jang ${ }^{1}$, Jeonghyun Kim ${ }^{2, *(1)}$ and Alena Sicakova ${ }^{3}$ (i) \\ 1 Architecture Office 1, Seoul Metro, Hyoryeong-ro 5, Seoul 06693, Korea; null91314@seoulmetro.co.kr \\ 2 Faculty of Civil Engineering, Wrocław University of Science and Technology, Wybrzeże Wyspiańskiego 27, \\ 50-370 Wrocław, Poland \\ 3 Faculty of Civil Engineering, Technical University of Kosice, Vysokoskolska 4, 04200 Kosice, Slovakia; \\ alena.sicakova@tuke.sk \\ * Correspondence: jeonghyun.kim@pwr.edu.pl
}

Citation: Jang, H.; Kim, J.; Sicakova, A. Effect of Aggregate Size on Recycled Aggregate Concrete under Equivalent Mortar Volume Mix Design. Appl. Sci. 2021, 11, 11274. https://doi.org/10.3390/app112311274

Academic Editor: Dario De Domenico

Received: 19 October 2021

Accepted: 26 November 2021

Published: 28 November 2021

Publisher's Note: MDPI stays neutral with regard to jurisdictional claims in published maps and institutional affiliations.

Copyright: (c) 2021 by the authors. Licensee MDPI, Basel, Switzerland. This article is an open access article distributed under the terms and conditions of the Creative Commons Attribution (CC BY) license (https:// creativecommons.org/licenses/by/ $4.0 /)$.

\begin{abstract}
In this paper, the effect of the original aggregate size of the recycled aggregate on the mechanical properties of the recycled aggregate concrete was evaluated. A series of concretes were produced in which natural aggregates, recycled aggregates, and original aggregates in recycled aggregates were matched for a single particle size distribution curve. The replacement levels of recycled aggregate were $25 \%$ and $50 \%$, and equivalent mortar volume mix design was applied for recycled aggregate concrete. The results show that the mechanical strength of recycled aggregate concrete increases with increasing original aggregate size. This effect was observed to be greater in concrete using recycled aggregate with a high residual mortar content.
\end{abstract}

Keywords: recycled concrete aggregate; original aggregate; recycled aggregate concrete; concrete mix design; equivalent mortar volume; aggregate size; particle size distribution

\section{Introduction}

Coarse aggregate occupies the largest volume of raw materials in concrete [1], and is one of the major parameters that can significantly affect the performance of concrete [2]. Therefore, various characteristics such as shape [3], size [4], surface condition [5,6], and type [7] of coarse aggregate have been investigated worldwide. Several studies have shown that the strength of normal concrete increases as the nominal maximum aggregate size increases [8,9]. Haque et al. [10] reported that the higher the fineness modulus of coarse aggregate, the higher the compressive strength at the same nominal size. However, when using aggregates with sizes larger than a certain threshold, a decrease in strength is observed. Hossain et al. [11] found that the compressive strength of concretes made with maximum aggregates sizes of 19,25 , and $32 \mathrm{~mm}$ was $6-10 \%$ higher than that of concrete with a maximum size of $12.5 \mathrm{~mm}$, whereas the strength of concrete with the maximum size of 38 and $50 \mathrm{~mm}$ showed a decreasing trend. Conversely, the literature [12,13] has reported that concrete with a smaller size of aggregates (e.g., $10 \mathrm{~mm}$ compared to 13,19, and $25 \mathrm{~mm}$ ) has higher strength. This is associated with an increase in the interfacial transition zone (ITZ), which is considered the weakest phase of concrete where microcracks are most likely to exist as the aggregate size increases [14].

For the sake of sustainability, various recyclable materials (concrete, brick, glass) and industrial by-products (steel and furnace slag) have been studied as substitutes for natural aggregates (NA) $[15,16]$. In particular, real-scale experiments have been performed to evaluate the applicability of concrete containing recycled concrete aggregate (RCA) and materials such as electric arc furnace slag for reinforced concrete elements $[17,18]$. Although the applicability of recyclable materials as a substitute for NA is obvious, a difference has been observed in the replacement ratio. Some researchers have recommended a replacement of up to $30 \%$, while others have noted that a full replacement could be 
feasible [16]. This is because recycled materials used as alternative aggregates have different physical and chemical properties from NA, which is one of the necessities of extensive research on recycled materials.

When NA is replaced by RCA, the concrete matrix becomes more complex. RCA is composed of original aggregate $(\mathrm{OA})$ and residual mortar, and the residual mortar is the fundamental cause of the poor quality of RCA than that of NA [19]. It has been shown that the amount of residual mortar depends on the grain size of RCA [20,21]. According to [22], in the coarse fractions, $10-20 \mathrm{~mm}$, the habitual values range between $23-52 \%$, whereas in the finer fraction, they can ascend up to $32-61 \%$. In this context, grains of different sizes then have different effects on the properties of the new concrete. In the literature [23], compared with the corresponding parent concrete, the strength reduction in recycled aggregate concrete (RAC) with the maximum RCA size of $10 \mathrm{~mm}$ was $20-35 \%$, and as for RCA sizes of $20 \mathrm{~mm}$ and $40 \mathrm{~mm}$, the strength loss was $14-35 \%$ and $10-25 \%$, respectively. The authors of that study concluded that a smaller maximum size of RCA resulted in a greater reduction in the strength of RAC due to an increase in the amount of old residual mortar present in RCA. Xia et al. [24] measured the compressive strength and tensile strength of concrete using RCAs with maximum aggregate sizes of 9.5, 19, and $31.5 \mathrm{~mm}$. The results showed that RAC with a maximum aggregate size of $19 \mathrm{~mm}$ had the highest strength, and RAC made with a maximum size of $31.5 \mathrm{~mm}$ had the lowest strength. On the other hand, McGinnis et al. [25] reported that smaller aggregates made concrete about 10-15\% stronger. Moreover, Basheer et al. [26] stated that smaller sized aggregates are preferable to design durable concrete. According to the above literature review, the effect of the RCA size on the properties of concrete seems ambiguous, thus, more research is needed in depth. This may be associated with the fact that the increase in the RCA size includes both favorable (e.g., enhanced RCA quality) and unfavorable factors (e.g., increasing ITZ and heterogeneity in RAC matrix) to the properties of concrete.

Residual mortar unfavorably affects RCA quality and performance of RAC. Recently, several researchers have reported that the properties of RAC can be improved by applying an appropriate mix design for RAC called the equivalent mortar volume (EMV) mix design [18,27-31]. In the EMV mix design, the residual mortar of RCA is considered as mortar, and the OA of RCA is considered as actual aggregate for mixture proportioning. However, these studies did not investigate the influence of OA size. In some publications [32-35], residual mortar content in excess of 50\% was observed. Given that smaller RCA has higher residual mortar content, in practice, the small size of RCA may contain little or no OA. Theoretically, due to the presence of residual mortar, although the apparent particle size of RCA looks similar to that of NA, the actual size of OA is inevitably smaller than that of RCA. In particular, for RCA with high residual mortar content, the OA size becomes smaller. Therefore, in this study, in order to evaluate the effect of the OA size in RCA on properties of RAC, the particle size of RCA and OA was determined using the residual mortar removal method, respectively, and the fresh and hardened characteristics were investigated.

As discussed above, the size of the aggregates is associated with the homogeneity and ITZ of the concrete material, affecting the mechanical strength in some way. For normal strength concrete, when aggregates with a maximum nominal size of $13-19 \mathrm{~mm}$ are used, the mechanical strength of concrete appears to be high. However, the existing literature does not consider the effect of OA in RCA. The significance of the paper lies primarily in the consideration of this parameter in the experimental course, so that the obtained results can be clues to improve the low performance of RAC.

\section{Materials and Methods}

\subsection{Materials}

Ordinary Portland cement corresponding to Korean Standards (KS) Type I [36] was used. Density and specific surface area of the OPC were $3.14 \mathrm{~g} / \mathrm{cm}^{3}$ and $3550 \mathrm{~cm}^{2} / \mathrm{g}$, respectively. 
Natural crushed granite aggregate produced in the quarry was used as NA. For natural fine aggregate (NFA), natural siliceous river sand with round and smooth particles was used. The specific gravity and water absorption were 2.53 and $0.91 \%$, respectively.

Two types of RCAs (RCA1 and RCA2) with a nominal maximum aggregate size of $25 \mathrm{~mm}$ were selected from the RCA processing plant: RCA1 from a concrete road and RCA2 from unknown sources. As a result of visual inspection, no foreign substances other than aggregate, mortar, and concrete were found in the RCAs. The RCAs were transferred to the laboratory in ton bags, and were classified by size $(9.5,13,19$, and $25 \mathrm{~mm})$ to evaluate material properties for each size. Water absorption and specific gravity were performed as per KS F2503 [37]. The aggregates used in the study are shown in Figure 1 and the material characteristics are summarized in Table 1 . The average specific gravity and water absorption of RCA1 were 2.41 and $5.28 \%$, and for RCA2 of 2.53 and $2.54 \%$, respectively.

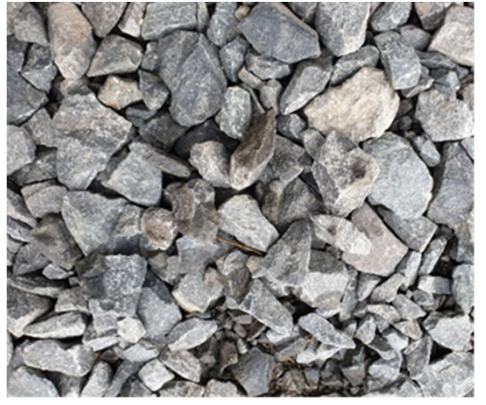

(a) Natural aggregate

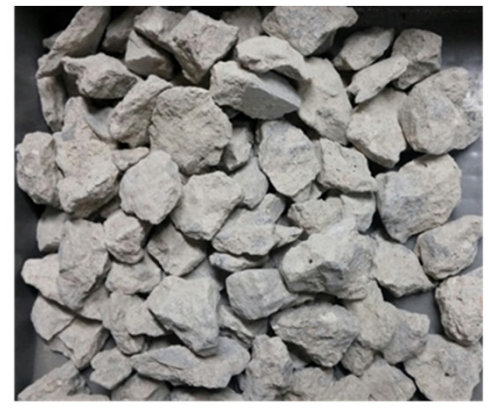

(b) Recycled aggregate 1

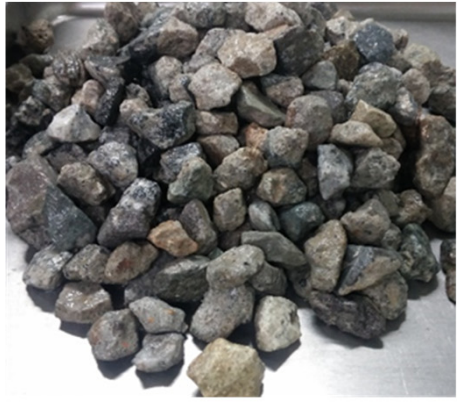

(c) Recycled aggregate 2

Figure 1. Natural and recycled aggregates used in the study. (a) NA; (b) RCA1; (c) RCA2.

Table 1. Physical properties of coarse and fine aggregates.

\begin{tabular}{ccccc}
\hline Aggregate & Size (mm) & $\begin{array}{c}\text { Water } \\
\text { Absorption (\%) }\end{array}$ & Specific Gravity & RMC (\%) \\
\hline NA & $4.75-19$ & 0.95 & 2.66 & - \\
\hline \multirow{2}{*}{ RCA1 } & $19-25$ & 4.20 & 2.46 & 21.7 \\
& $13-19$ & 4.83 & 2.44 & 27.7 \\
& $9.5-13$ & 5.48 & 2.39 & 32.2 \\
& $4.75-9.5$ & 6.61 & 2.36 & 28.6 \\
& Average & 5.28 & 2.41 & 10.8 \\
RCA2 & $19-25$ & 2.62 & 2.52 & 13.7 \\
& $13-19$ & 2.23 & 2.55 & 14.5 \\
& $9.5-13$ & 2.45 & 2.54 & 12.0 \\
\hline & $4.75-9.5$ & 2.86 & 2.52 & - \\
\hline
\end{tabular}

Concrete preparation using the EMV mix design method requires quantification of residual mortar attached to RCA. The residual mortar content was determined by the mechanical and chemical stress method developed by Abbas et al. [38]. RCA samples of individual size fractions were prepared for this experiment, and the sample mass was approximately $2000 \mathrm{~g}$ for the $19-25 \mathrm{~mm}$ size fraction and $1000 \mathrm{~g}$ for the remaining size fractions. RCA samples dried in an oven at $110{ }^{\circ} \mathrm{C}$ for $24 \mathrm{~h}$ were weighed (M1) and immersed in sodium sulfate solution for $24 \mathrm{~h}$. While immersed in sodium sulfate solution, the RCA samples were subjected to a total of five cycles of freezing at $-17^{\circ} \mathrm{C}$ for $16 \mathrm{~h}$ and thawing at $80{ }^{\circ} \mathrm{C}$ for $8 \mathrm{~h}$. After the last cycle, the solution was drained and the samples were washed with water. The RCA smaller than $4.75 \mathrm{~mm}$ was removed. After that, the washed and sieved samples were placed in an oven to dry and then weighed (M2). The 
quantity of residual mortar was determined by Equation (1) as residual mortar content (RMC).

$$
\mathrm{RMC}(\%)=[(\mathrm{M} 1-\mathrm{M} 2) / \mathrm{M} 1] \times 100
$$

As seen in Table 1, a residual mortar content can be significantly different depending on the actual RCA source and probably also the way of crushing (28.6\% for RCA1 and $12.0 \%$ for RCA2). However, the same trend was found for both samples with regard to the relationship between grain size and the amount of residual mortar: a higher residual mortar content was in the small particle size RCA, resulting in higher water absorption and lower specific gravity. Similar results have been reported in $[39,40]$. This may be because the RCA of a small fraction contained the residual mortar that fell off the concrete mass during the RCA production.

\subsection{Particle Size Determination}

For the determination of particle size distribution, the representative samples of NA and RCA were selected and sieved as per KS F2502 [41].

In order to determine the particle size distribution of OA in RCA, the residual mortar in RCA was removed using a hydrochloric acid solution. The RCA used for particle size distribution analysis was immersed in a hydrochloric acid solution with a concentration of $1 \mathrm{M}(\mathrm{mol} / \mathrm{L})$ for $24 \mathrm{~h}$ to dissolve residual mortar from OA [27,42]. The acid treatment is less time-consuming than the method for calculating residual mortar content proposed by Abbas et al. [38] and has the advantage of handling large amounts of RCA in one treatment. Removal of residual mortar by the hydrochloric acid solution can dissolve calcareous aggregates, thus, special attention is required in the selection of the method [39]. Since the OA of the RCA used in this study was granite, which is generally considered to have strong acid resistance, the hydrochloric acid dissolution method was applied. The obtained OA was washed with tap water and then sieved to determine the particle size distribution curve. The particle size distributions of RCA and OA are shown in Figure 2. The RCA-AP denotes the apparent particle size distribution of RCA itself. The distribution curve for OA is denoted as RCA-OA. As expected, the size of the OA was smaller than that of the corresponding RCA, and the particle size reduction was greater in the RCA1 with the residual mortar content of $28.6 \%$ than in the RCA2 with the residual mortar content of $12 \%$. The maximum nominal aggregate size of both RCA1 and RCA2 was $25 \mathrm{~mm}$, but that of the original aggregates (RCA1-OA and RCA2-OA) was $19 \mathrm{~mm}$.

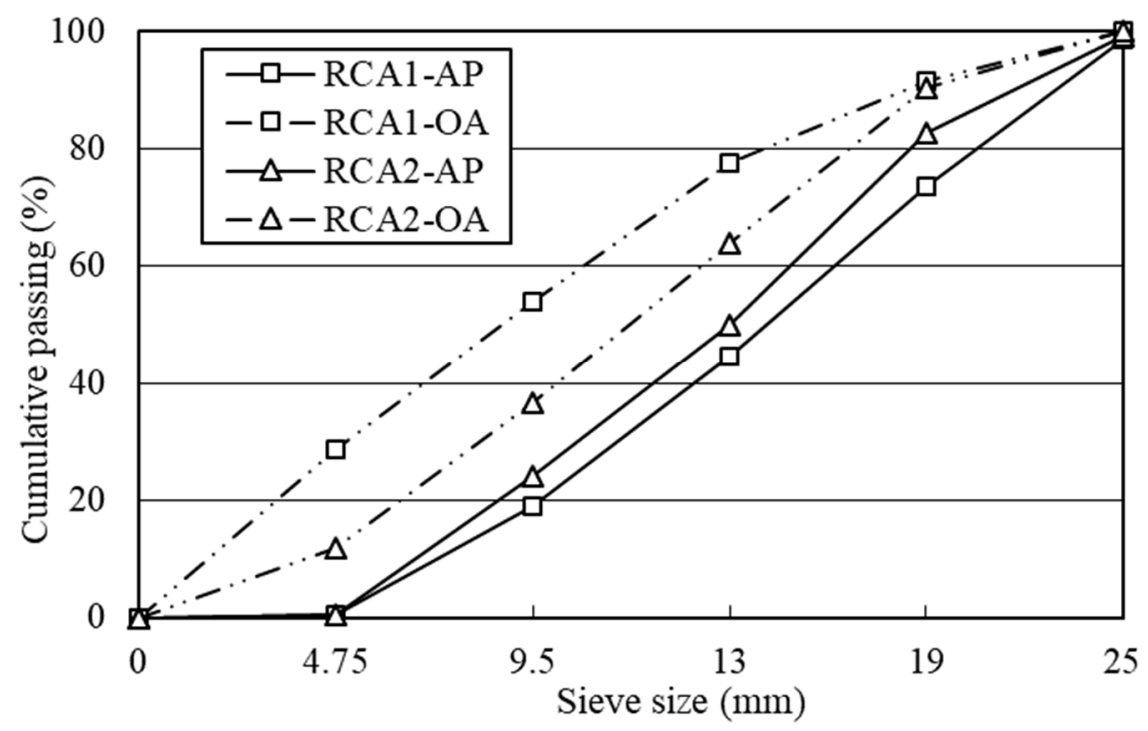

Figure 2. Results of the sieve analysis of recycled aggregates and original aggregates. 
In order to investigate the effect of the OA size, the particle size distribution of all aggregates to be used for making concrete specimens should be the same. Therefore, the particle size distribution of NA and RCA was matched to the particle size distribution of OA. For example, the RCA1-AP was obtained by manually matching the RCA1 to the RCA1-OA particle size distribution shown in Figure 2. When RAC is produced tailored to the RCA1-AP curve using RCA1 in the size range of $4.75-25 \mathrm{~mm}$, the RAC actually has the particle size distribution of RCA1-OA shown in Figure 2. In this way, RCAs were prepared for the experiment and used for RAC mixing; the following is an explanation of the types and their designations:

- $\quad$ RAC-AP: Concrete in which the RCA with a particle size range of 4.75-25 mm was manually fitted to the same particle size curve as OA $(4.75-19 \mathrm{~mm})$ (i.e., $19 \mathrm{~mm}$ is its apparent size).

- $\quad$ RAC-OA: Concrete in which the RCA with a particle size range of 4.75-25 mm was used without any modification (i.e., the aggregate contains OA of $4.75-19 \mathrm{~mm}$ inside).

\subsection{Mix Design and Test Methods}

A total of 10 concrete mixtures (two natural aggregate concretes and eight RACs) with a target compressive strength of $30 \mathrm{MPa}$ at 28 days were designed. The $0 \% \mathrm{RA}$ replacement rate represents natural aggregate concrete (NAC) designed according to the ACI standard, representing a control mix. RACs were designed according to the EMV mix design [28], with replacement rates of $25 \%$ and $50 \%$. The water-cement ratio was 0.45 for all mixtures. The superplasticizer was added as $1 \%$ by mass of cement.

The EMV mix design was proposed by Fathifazl [43] to improve the properties of RAC. Figure 3 shows the mix proportions of NAC and RAC designed by the conventional mix design and the EMV mix design. In the conventional mix design, RCA itself is considered as a coarse aggregate. For this reason, the author noted that the mortar volume of RAC produced by the conventional mixed design method was larger than that of NAC. The main feature of the EMV method is to consider the residual mortar of RCA as part of the mortar of concrete. Therefore, RAC made with the EMV mix design has the same mortar volume as NAC (see Table 2). A detailed description of the EMV mix design can be found in $[28,43]$.

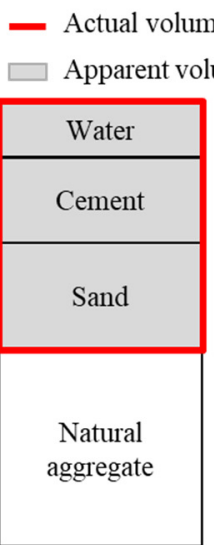

(a) Natural aggregate concrete

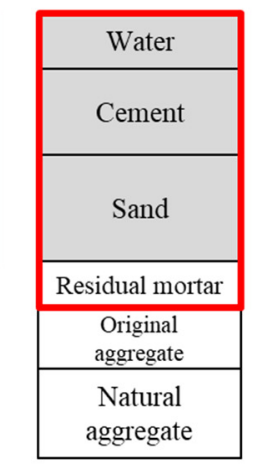

(b) Conventional

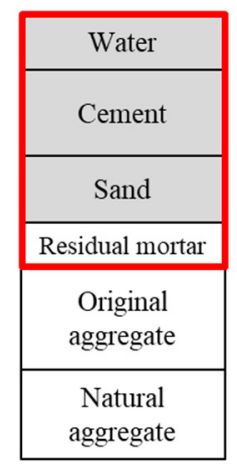

(c) EMV mix design

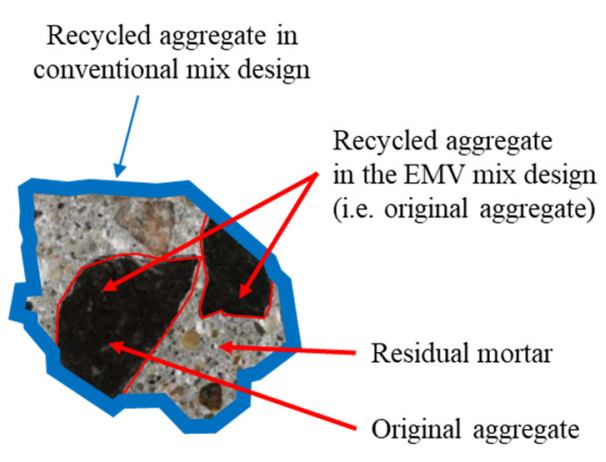

mix with RCA

Figure 3. Illustration of the EMV concept for the mix design of concretes with recycled aggregates.

The procedure of the EMV mix design involved a series of calculations, an example of which is given in Appendix A. Table 2 shows volumetric mix proportions of concrete mixtures used in the study according to the EMV mix design. The same volume applies to the RAC-OA series. 
Table 2. Mix proportions of concretes by volume.

\begin{tabular}{|c|c|c|c|c|c|c|c|c|}
\hline \multirow{2}{*}{ ID } & \multirow{2}{*}{ Size $(\mathrm{mm})$} & \multirow{2}{*}{ RCA (\%) } & \multirow{2}{*}{ Water $\left(\mathrm{m}^{3}\right)$} & \multirow{2}{*}{ Cement $\left(\mathrm{m}^{3}\right)$} & \multirow{2}{*}{ Sand $\left(\mathrm{m}^{3}\right)$} & \multicolumn{2}{|c|}{$\operatorname{RCA}\left(\mathrm{m}^{3}\right)$} & \multirow{2}{*}{$\mathrm{NA}\left(\mathrm{m}^{3}\right)$} \\
\hline & & & & & & RMC & OA & \\
\hline \multicolumn{9}{|c|}{ Apparent Volume of Mortar } \\
\hline & & & \multicolumn{4}{|c|}{ Volume of Mortar According to EMV Concept } & \multicolumn{2}{|c|}{ Volume of Coarse Aggregates } \\
\hline NAC & $4.75-19$ & 0 & & 0.619 & & 0 & 0 & 0.381 \\
\hline \multirow{3}{*}{ RAC1-AP-25 } & \multirow{3}{*}{$4.75-19$} & \multirow{3}{*}{25} & \multirow{2}{*}{\multicolumn{3}{|c|}{0.567}} & \multicolumn{2}{|c|}{0.147} & \multirow{2}{*}{0.286} \\
\hline & & & & & & 0.052 & 0.095 & \\
\hline & & & \multicolumn{3}{|c|}{0.619} & & \multicolumn{2}{|c|}{0.381} \\
\hline \multirow{3}{*}{ RAC1-AP-50 } & \multirow{3}{*}{$4.75-19$} & \multirow{3}{*}{50} & \multirow{2}{*}{\multicolumn{3}{|c|}{0.516}} & & & \multirow{2}{*}{0.191} \\
\hline & & & & & & 0.103 & 0.191 & \\
\hline & & & \multicolumn{3}{|c|}{0.619} & & \multicolumn{2}{|c|}{0.381} \\
\hline \multirow{3}{*}{ RAC2-AP-25 } & \multirow{3}{*}{$4.75-19$} & \multirow{3}{*}{25} & \multirow{2}{*}{\multicolumn{3}{|c|}{0.598}} & & & \multirow{2}{*}{0.286} \\
\hline & & & & & & 0.021 & 0.095 & \\
\hline & & & \multicolumn{3}{|c|}{0.619} & & \multicolumn{2}{|c|}{0.381} \\
\hline \multirow{3}{*}{ RAC2-AP-50 } & \multirow{3}{*}{$4.75-19$} & \multirow{3}{*}{50} & & 0570 & & & & 0191 \\
\hline & & & & $0.0 / 8$ & & 0.041 & 0.191 & 0.191 \\
\hline & & & & 0.6 & & & & \\
\hline
\end{tabular}

Natural coarse and fine aggregate were in the saturated surface-dry (SSD) condition before mixing. RCA requires pre-wetting due to its high water absorption, but using RCA in the SSD state for concrete is unfavorable to the mechanical strength of RAC [44-46]. Therefore, the water-saturated RCA was dried in air for $24 \mathrm{~h}$ before mixing to contain sufficient moisture but not completely saturated.

The detailed mix proportions of concretes are shown in Table 3: Control mixtures with $100 \%$ of NA having the particle size distribution of RCA1-OA and RCA2-OA (NAC1 and NAC2); four RAC mixtures in which the apparent size and the apparent particle size distribution of the partially replaced RCA was identical to the particle size distribution of the OA (RAC1-AP-25, RAC2-AP-25, RAC1-AP-50, and RAC2-AP-50); four RAC mixtures in which the apparent size of partially replaced RCA was $25 \mathrm{~mm}$ while having the OA particle size distribution inside (RAC1-OA-25, RAC2-OA-25, RAC1-OA-50, and RAC2-OA-50).

Table 3. Mix proportions of concrete.

\begin{tabular}{|c|c|c|c|c|c|c|c|}
\hline ID & Size (mm) & RCA (\%) & Water (kg) & Cement (kg) & Sand (kg) & NA (kg) & RCA (kg) \\
\hline NAC1 & $4.75-19$ & 0 & 175 & 389 & 720 & 1003 & 0 \\
\hline NAC2 & $4.75-19$ & 0 & 175 & 389 & 720 & 1003 & 0 \\
\hline RAC1-AP-25 & $4.75-19$ & 25 & 160 & 357 & 660 & 752 & 336 \\
\hline RAC1-AP-50 & $4.75-19$ & 50 & 146 & 324 & 600 & 502 & 673 \\
\hline RAC2-AP-25 & $4.75-19$ & 25 & 169 & 376 & 696 & 752 & 286 \\
\hline RAC2-AP-50 & $4.75-19$ & 50 & 163 & 363 & 672 & 502 & 572 \\
\hline RAC1-OA-25 & $4.75-25$ & 25 & 160 & 357 & 660 & 752 & 336 \\
\hline RAC1-OA-50 & $4.75-25$ & 50 & 146 & 324 & 600 & 502 & 673 \\
\hline RAC2-OA-25 & $4.75-25$ & 25 & 169 & 376 & 696 & 752 & 286 \\
\hline RAC2-OA-50 & $4.75-25$ & 50 & 163 & 363 & 672 & 502 & 572 \\
\hline
\end{tabular}

All the concrete mixtures were prepared in a pan mixer with a capacity of $60 \mathrm{~L}$. The coarse and fine aggregates were put in the mixer and mixed for $30 \mathrm{~s}$, then cement was 
added and mixed for $90 \mathrm{~s}$. Afterward, water and superplasticizer were added and mixed for a further $120 \mathrm{~s}$ to obtain homogeneous concrete mixtures.

The slump and air content of fresh concretes were performed according to KS F2402 and F2421 [47,48]. All concrete mixtures were cast into plastic molds, demolded $24 \mathrm{~h}$ after casting, and cured in water before testing. For hardened properties, compressive strength, elastic modulus, and splitting tensile strength were tested according to KS F2405, F2438, and F2423 [49-51]. The evolution of compressive strength was observed at 7, 28, and 56 days using standard cylindrical specimens with a size of $100 \times 200 \mathrm{~mm}$, and the elastic modulus was measured using two strain gauges simultaneously with compressive strength. Splitting tensile strength was measured at 28 and 56 days. Three specimens were tested for each property of hardened concrete.

\section{Results and Discussion}

The test results for the fresh and hardened mechanical properties of concrete are summarized in Table 4.

Table 4. Fresh and hardened properties of concrete mixtures (' \pm ' indicates the standard deviation).

\begin{tabular}{|c|c|c|c|c|c|c|c|c|c|c|}
\hline \multirow[t]{2}{*}{ ID } & \multirow[t]{2}{*}{$\begin{array}{l}\text { Slump } \\
(\mathrm{mm})\end{array}$} & \multirow{2}{*}{$\begin{array}{c}\text { Air } \\
\text { Content } \\
(\%)\end{array}$} & \multicolumn{3}{|c|}{ Compressive Strength (MPa) } & \multicolumn{2}{|c|}{$\begin{array}{l}\text { Splitting Tensile Strength } \\
\text { (MPa) }\end{array}$} & \multicolumn{3}{|c|}{ Elastic Modulus (GPa) } \\
\hline & & & 7-Day & 28-Day & 56-Day & 28-Day & 56-Day & 7-Day & 28-Day & 56-Day \\
\hline NAC1 & 110 & 4.3 & $26.6 \pm 0.8$ & $32.7 \pm 1.0$ & $35.4 \pm 1.4$ & $2.90 \pm 0.14$ & $3.20 \pm 0.10$ & $24.2 \pm 1.1$ & $25.8 \pm 1.7$ & $27.4 \pm 1.4$ \\
\hline NAC2 & 105 & 4.5 & $26.8 \pm 1.0$ & $33.0 \pm 1.3$ & $35.8 \pm 0.7$ & $2.88 \pm 0.22$ & $3.17 \pm 0.15$ & $24.4 \pm 0.9$ & $25.9 \pm 0.9$ & $27.0 \pm 1.0$ \\
\hline $\begin{array}{l}\text { RAC1- } \\
\text { AP-25 }\end{array}$ & 85 & 4.4 & $26.2 \pm 0.9$ & $30.8 \pm 1.3$ & $33.5 \pm 1.6$ & $2.87 \pm 0.19$ & $3.06 \pm 0.10$ & $24.4 \pm 1.0$ & $26.0 \pm 0.9$ & $28.2 \pm 1.2$ \\
\hline $\begin{array}{l}\text { RAC1- } \\
\text { AP-50 }\end{array}$ & 60 & 4.8 & $25.8 \pm 1.1$ & $30.5 \pm 1.6$ & $33.4 \pm 0.9$ & $2.80 \pm 0.18$ & $3.05 \pm 0.07$ & $24.3 \pm 1.2$ & $25.5 \pm 1.3$ & $27.8 \pm 0.9$ \\
\hline $\begin{array}{l}\text { RAC2- } \\
\text { AP-25 }\end{array}$ & 105 & 4.6 & $27.4 \pm 1.3$ & $33.2 \pm 1.5$ & $35.4 \pm 1.4$ & $2.88 \pm 0.15$ & $3.18 \pm 0.09$ & $24.7 \pm 1.3$ & $27.4 \pm 1.6$ & $29.9 \pm 1.7$ \\
\hline $\begin{array}{l}\text { RAC2- } \\
\text { AP-50 }\end{array}$ & 85 & 4.4 & $28.2 \pm 1.1$ & $34.0 \pm 1.3$ & $37.3 \pm 2.0$ & $2.94 \pm 0.07$ & $3.23 \pm 0.16$ & $25.0 \pm 1.5$ & $28.2 \pm 1.8$ & $30.5 \pm 1.9$ \\
\hline $\begin{array}{l}\text { RAC1- } \\
\text { OA-25 }\end{array}$ & 85 & 4.6 & $27.0 \pm 1.2$ & $31.1 \pm 1.1$ & $34.2 \pm 1.9$ & $2.92 \pm 0.13$ & $3.06 \pm 0.11$ & $24.2 \pm 0.6$ & $27.6 \pm 1.4$ & $29.2 \pm 1.7$ \\
\hline $\begin{array}{l}\text { RAC1- } \\
\text { OA-50 }\end{array}$ & 65 & 4.8 & $27.7 \pm 0.7$ & $32.9 \pm 1.2$ & $34.4 \pm 1.3$ & $3.00 \pm 0.11$ & $3.16 \pm 0.18$ & $25.0 \pm 0.6$ & $28.8 \pm 1.2$ & $29.6 \pm 1.9$ \\
\hline $\begin{array}{l}\text { RAC2- } \\
\text { OA-25 }\end{array}$ & 90 & 4.6 & $27.2 \pm 1.6$ & $33.5 \pm 1.2$ & $35.3 \pm 1.6$ & $3.18 \pm 0.14$ & $3.28 \pm 0.12$ & $23.8 \pm 1.7$ & $29.0 \pm 1.7$ & $31.1 \pm 1.2$ \\
\hline $\begin{array}{l}\text { RAC2- } \\
\text { OA-50 }\end{array}$ & 80 & 4.4 & $29.0 \pm 1.4$ & $35.5 \pm 0.9$ & $38.2 \pm 1.2$ & $3.24 \pm 0.17$ & $3.41 \pm 0.17$ & $25.2 \pm 1.5$ & $31.0 \pm 1.2$ & $33.3 \pm 2.0$ \\
\hline
\end{tabular}

\subsection{Fresh Properties}

The slump and air contents for each concrete mixture are given in Table 4. The decrease in the slump value was found to increase as the RCA replacement levels were increased. The slump values of RAC1-AP-25 and RAC1-OA-25 using RCA1 with $28 \%$ residual mortar content were $23 \%$ lower than that of the control mixture (NAC1), and at 50\% replacement level, the slump loss was $41-45 \%$. For the RAC2 series using RCA2 with $12 \%$ residual mortar content, the slump decreased by $14 \%$ than that of the control mixture at $25 \%$ RCA replacement level, at $50 \%$ replacement, the slump was reduced by up to $24 \%$. Therefore, the use of RCA with a low amount residual mortar can alleviate the slump loss. The lower slump values of RAC compared to NAC are commonly reported in previous studies $[52,53]$ and can be attributed to the following reasons: (i) high water absorption of RCA; and (ii) reduction in the amount of cement and fine aggregate due to the application of the EMV mix design. At 50\% replacement ratio, the slump ranged from 60 to $85 \mathrm{~mm}$, which satisfies the minimum slump requirement of $80 \pm 25 \mathrm{~mm}$ for normal weight concrete with a maximum aggregate size of 20 and $25 \mathrm{~mm}$ according to KS F4009 [54] and practically means a medium workability suitable for standard compaction techniques such as vibration. In addition, by optimizing workability for a specific on-site technology, workability can be improved by using plasticizers. 


\subsection{Hardened Properties}

\subsubsection{Compressive Strength}

The compressive strength after 7,28 , and 56 days of the concrete mixtures tested in this study is shown in Figure 4. All RAC mixes achieved the target strength of $30 \mathrm{MPa}$, which means that RACs designed with the EMV mix design can be used as structural concrete members.
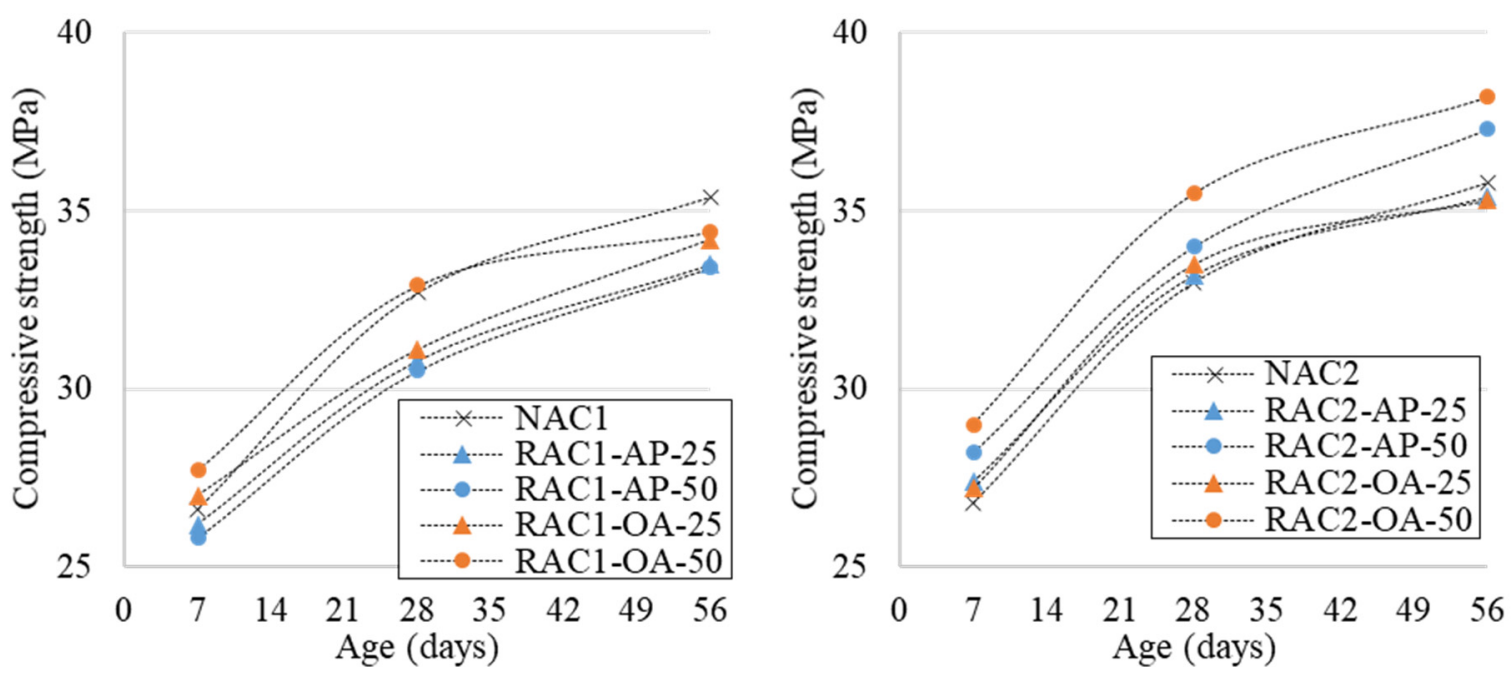

Figure 4. Compressive strength development with age.

The 7-day compressive strength of RAC1 was in the range of $\pm 3 \%$ of that of the control concrete, NAC1. However, after 28 days, only RAC1-OA-50 exhibited similar behavior to the reference specimen, and about 5-7\% strength loss was observed with the other RAC1 mixes. Additionally, at 56 days, all RAC1 mixes showed lower compressive strength than NAC1, with a loss percentage of up to $6 \%$. These decreases in strength practically mean a shift of one strength class (e.g., at a strength of $30 \mathrm{MPa}$ (strength class 30 according Korean standard), a decrease in strength of $7 \%$ is $2.1 \mathrm{MPa}$; the resulting value of $27.9 \mathrm{MPa}$ can be assigned to strength class 27). For RAC2, nearly similar and even higher compressive strength than that of NAC2 were observed at all ages. At seven and 28 days, the compressive strength of the RAC2 mixture was 1-8\% higher than that of the control mixture, NAC2. At 56 days, the compressive strength of the RAC2 mixture was in the range of $99-107 \%$. This can be attributed to the fact that the quality of the RA used for the RAC2 series is superior to that of the RA used in the RAC1 series. The RA quality is a major factor influencing the compressive strength of concrete, which is also in effect in concrete made by the EMV mix design [31]. In general, RAC causes a significant loss of mechanical strength depending on the RA replacement rate [32,55], but the EMV method allows it to achieve a mechanical performance similar to that of NAC. These results are consistent with other several studies [56,57].

Due to the nature of the EMV mixing design method, the unit mortar volume and the unit aggregate volume of concrete were constant irrespective of the RCA replacement rate. Therefore, the loss of strength in RAC with increasing replacement rate may not be significant compared to RAC proportioned by the traditional mix design. However, the effect of the maximum nominal size of aggregates was clearly observed for both RAC1 and RAC2. At a 25\% RA replacement rate, the compressive strength of RAC1-OA-25 in which the 4.75-25 mm fraction of RCA was used was about 1-3\% higher than that of RAC1-AP-25 in which 4.75-19 mm fraction was used. Additionally, when the replacement rate was increased to $50 \%$, the compressive strength increased by up to $8 \%$. For the RAC2 series, the effect of the maximum aggregate size was not as significant as for RAC1. At $25 \%$ and $50 \%$ replacement rates, the 28 -day compressive strength of the RAC2-OA series 
was $1-4 \%$ higher than that of the RAC2-AP series. The relatively less improved strength of RAC2 compared to RAC1 can be associated with the properties of RCA. This is because, compared to RCA1 with a residual mortar content of $27 \%$, RA2 with the residual mortar content of $12 \%$ had a smaller difference in size between OA and RCA.

\subsubsection{Splitting Tensile Strength}

The test results of splitting tensile strength for each RAC at 28 and 56 days are shown in Figure 5.
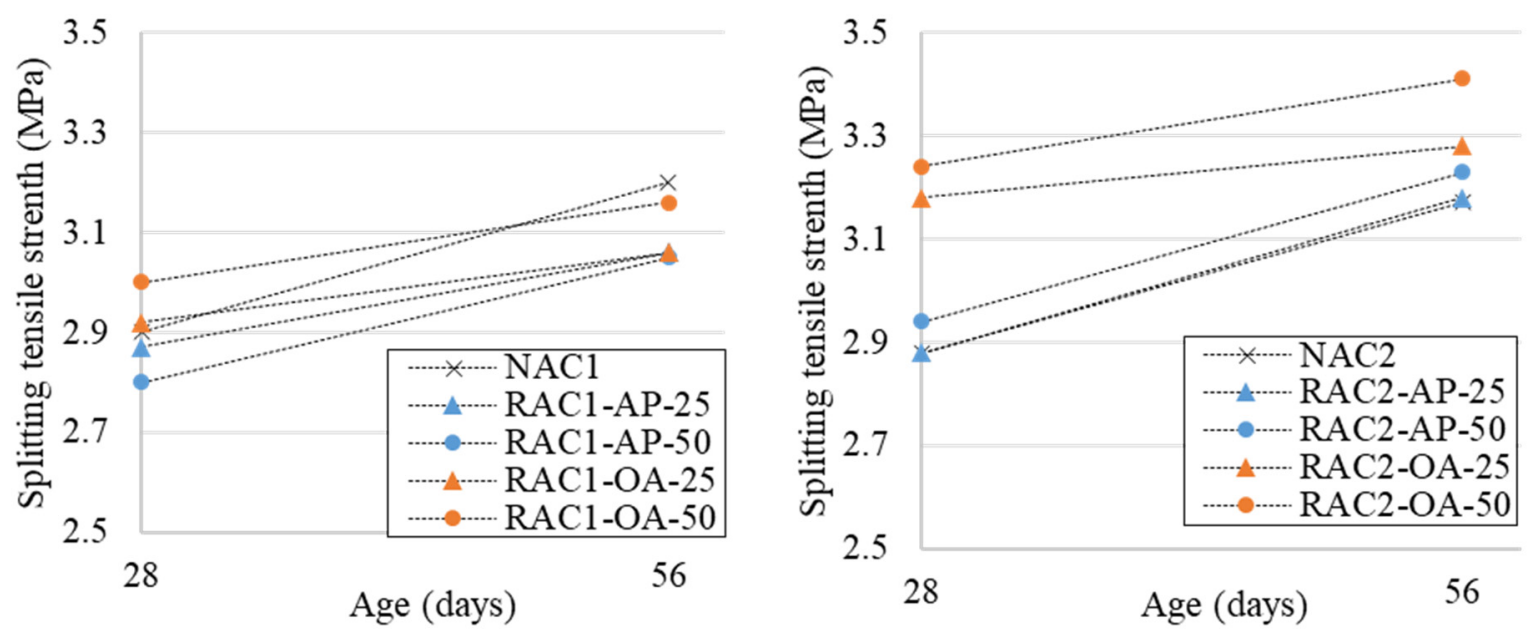

Figure 5. Splitting tensile strength development with age.

Although there are minor discrepancies among the test results with the time, the behavior of tensile strength is nearly similar to that of compressive strength. In the RAC1 series in which the RA quality was relatively low, RAC1-AP-25 and RAC1-AP-50 showed a $3-5 \%$ lower tensile strength than the control concrete at 28 and 56 days of age, whereas the RAC1-OA mixes showed 1-3\% higher tensile strength to control concrete at 28 days. The RAC2 series, made of high-quality RA, showed similar or slightly higher tensile strength than the control concrete in all RAC mixtures.

As can be seen in Figure 5, it seems that strength can be improved if the size of OA in RCA rather than RCA is large. The tensile strengths of RAC1-OA-25 and RAC1-OA-50 with a larger size of OA were $2 \%$ and $7 \%$ higher at 28 and 56 days, respectively, compared to the RAC1-AP series with smaller OA sizes. For RAC2, the RAC2-OA series had up to $10 \%$ improvement in tensile strength compared to the RAC2-AP series.

The correlation between compressive strength and splitting tensile strength of recycled aggregate concretes is shown in Figure 6. A comparison was made between the values calculated by the prediction model given in the ACI code (Equation (2)) and the actual experimental results performed in this study.

$$
f_{c t}=0.56 \sqrt{f_{c}}
$$

where $f_{c t}$ is the splitting tensile strength and $f_{c}$ is the compressive strength.

In Figure 6, the RAC1 and RAC2 were integrated into RAC, but were divided into the $\mathrm{AP}$ and $\mathrm{OA}$ series to evaluate the effect of maximum aggregate size. In the case of the RAC-OA series, in which concrete was manufactured based on the size of OA, a higher value of tensile strength was clearly observed than that of RAC-AP based on the size of RA itself at the same compressive strength level, but the ACI equation clearly overestimated the tensile strength obtained in all RAC mixtures. Although a low correlation coefficient (less than 0.5) between compressive strength and tensile strength has been observed in some studies [58], the RACs used in this study had good correlation coefficients ( 0.81 and 0.88). In particular, it is worth mentioning that a higher correlation coefficient was observed 
in the RAC-OA series, where the particle size distribution was determined based on OA. Therefore, when concrete is manufactured based on OA particle size, the properties of concrete can be more predictable.



Figure 6. Correlation between the compressive strength and splitting tensile strength of recycled aggregate concretes.

\subsubsection{Elastic Modulus}

The elastic modulus of the concrete mixes at 7, 28, and 56 days are given in Figure 7. Except for RAC1-AP-50 at 28 days, all concrete mixes showed higher values of elastic modulus than the control mix at 28 and 56 days. The RAC1-AP series had an elastic modulus in the range of $99-107 \%$ of NAC1, and the RAC1-OA series was in the range of $107-112 \%$. Compared with the control concrete (NAC2), the 28-day modulus of the RAC2-AP series with high-quality RA was $6 \%$ and $9 \%$ higher at $25 \%$ and $50 \%$ mixing rates, respectively, and the RAC2-OA series was $12 \%$ and $20 \%$ higher at the corresponding replacement levels.
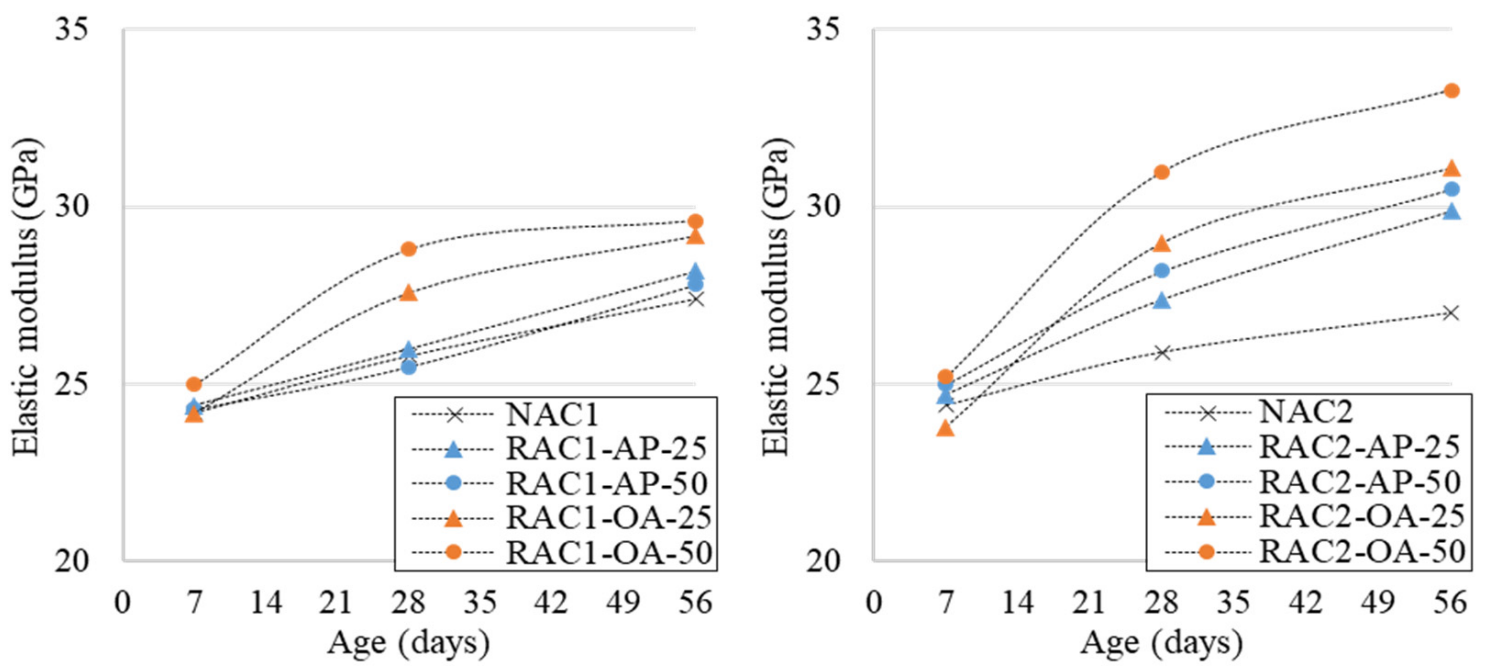

Figure 7. Elastic modulus development with age.

Interestingly, in terms of compressive and splitting tensile strength, the control mixture at 56 days showed higher strength than the RAC1 series, whereas, in terms of elastic modulus, all RAC1 series mixes were higher than the control mixtures. This is because 
the elastic modulus increases as the volume fraction of the aggregate increases [59]. In many studies, it has been reported that the compressive strength of RAC designed with the EMV mix design was lower than that of control concrete, but the elastic modulus was higher $[18,27,28,60]$.

The correlation between compressive strength $\left(f_{c}\right)$ and elastic modulus $\left(E_{c}\right)$ is plotted in Figure 8. In addition, Equation (3) for predicting the elastic modulus depending on the compressive strength of concrete provided in ACI 318-14 is shown in Figure 8.

$$
E_{c}=4700 \sqrt{f_{c}}
$$

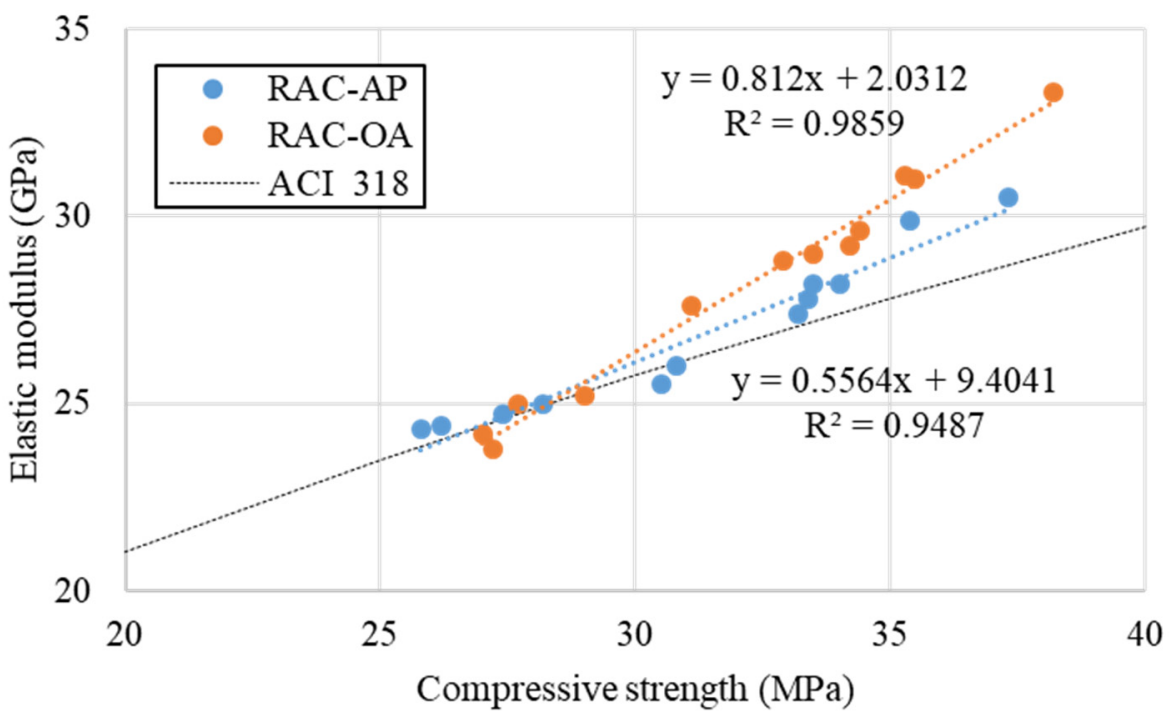

Figure 8. Correlation between compressive strength and elastic modulus of recycled aggregate concretes.

The $\mathrm{R}^{2}$ values of RAC-AP and RAC-OA were both above 0.9 , indicating that there were very strong correlations between compressive strength and elastic modulus. This could have a strong practical benefit for the prediction of elastic modulus based on compressive strength, since the strength test is standard, while the elastic modulus test is more technical and time-consuming. In the RACs used in this study, higher elastic modulus values than the prediction model were observed. However, according to the trend line, this equation might overestimate the modulus at a lower strength. At the same value of compressive strength, the RAC-OA series exhibited a higher elastic modulus than the RAC-AP series.

\section{Conclusions}

In this paper, the effect of the size of the original aggregates in recycled aggregates on the fresh and hardened properties of recycled aggregate concrete was evaluated. Based on the test results, the following conclusions were drawn:

- Higher residual mortar content was observed in the smaller size RCA, resulting in higher water absorption and lower specific gravity. The higher residual mortar content increased the size gap between the OA and RCA.

- The EMV mix design caused unfavorable workability of RAC in the fresh state, but it could improve the mechanical properties of RAC in the hardened state to a level similar to that of NAC.

- When the particle size distribution was determined based on the size of OA in RCA, the compressive strength, tensile strength, and elastic modulus of RAC designed by the EMV mix design were improved. 
- The RAC-OA series considering the size of OA showed stronger correlations between the compressive strength and splitting tensile strength, and the compressive strength and elastic modulus than the RAC-AP series considering the size of RCA itself.

Although the study presented was based on only two RCA samples from two different sources, they differed in their primary properties (absorbency, density, and residual mortar content) quite significantly, so they can be said to represent a wider range of potential RCA properties. The EMV mix design affects the results of the experiment because it practically (i) reduces the amount of new mortar and (ii) increases the amount of RCA, which naturally leads to their change. Provided that sufficient technical parameters are achieved, this would lead to savings in materials, especially cement and natural aggregate, and also to an increase in the recycling rate of construction and demolition waste. The principle of determining the mix proportions by the EMV method is applicable to any concrete with RCAs having a certain proportion of residual mortar.

However, further studies should be performed to generalize the results. This applies both to RCA from other sources and to the study of the EMV mix design principles in relation to the effect of OA size. Further research could also cover the use of the method to completely replace NA with RCA. Such substitutes are widely investigated by standard mix design methods and usually result in reduced mechanical properties (e.g., $20-25 \%$ reduction in compressive strength [61], up to $25 \%$ in tensile strength, and up to $15 \%$ in elastic modulus [62]).

Author Contributions: Conceptualization, J.K. and A.S.; Methodology, J.K.; Investigation, H.J.; Data curation, H.J. and J.K.; Writing—original draft preparation, H.J. and J.K.; Writing—-review and editing, A.S.; Supervision, A.S. All authors have read and agreed to the published version of the manuscript.

Funding: This research was carried out within the project of Slovak Scientific Grant Agency VEGA (Grant No. 1/0524/18) "Effective use of alternative aggregate of lower quality through modern concrete preparation techniques".

Institutional Review Board Statement: Not applicable.

Informed Consent Statement: Not applicable.

Data Availability Statement: Not applicable.

Conflicts of Interest: The authors declare no conflict of interest.

\section{Appendix A}

This appendix shows the EMV mix proportioning procedure of RAC1-AP-25.

1. Proportioning NAC based on the ACI mix design:

Weight of water in NAC : $W_{\text {Water }}^{\text {NAC }}=175 \mathrm{~kg}$

Weight of cement in NAC : $W_{\text {Cement }}^{\mathrm{NAC}}=389 \mathrm{~kg}$

Oven - dry weight of fine aggregate in NAC $: \mathrm{W}_{\mathrm{OD}-\mathrm{FA}}^{\mathrm{NAC}}=720 \mathrm{~kg}$

Oven - dry weight of NA in NAC: $\mathrm{W}_{\mathrm{OD}-\mathrm{NA}}^{\mathrm{NAC}}=1003 \mathrm{~kg}$

2. Calculating the required volume of NA in NAC and RAC, and RCA in RAC:

$$
\text { Volume of NA in NAC : } \mathrm{V}_{\mathrm{NA}}^{\mathrm{NAC}}=\frac{\mathrm{W}_{\mathrm{OD}-\mathrm{NA}}^{\mathrm{NAC}}}{\mathrm{SG}_{\mathrm{b}}^{\mathrm{NA}} \times 1000}=\frac{1003}{2.63 \times 1000}=0.381
$$

where $\mathrm{SG}_{\mathrm{b}}^{\mathrm{NA}}$ is the bulk specific gravity of NA $(=2.63)$

$$
\text { Volume of } \mathrm{NA} \text { in } \mathrm{RAC}: \mathrm{V}_{\mathrm{NA}}^{\mathrm{RAC}}=\mathrm{R} \times \mathrm{V}_{\mathrm{NA}}^{\mathrm{NAC}}=0.75 \times 0.381=0.286
$$

where $\mathrm{R}$ is a replacement ratio of NA by RCA

Volume of RCA in RAC : $\left.\left.\left.\mathrm{V}_{\mathrm{RCA}}^{\mathrm{RAC}}=\mathrm{V}_{\mathrm{NA}}^{\mathrm{NAC}} \times(1-\mathrm{R}) /\left[(1-\mathrm{RMC}) \times \frac{\mathrm{SG}_{\mathrm{b}}^{\mathrm{RCA}}}{\mathrm{SG}_{\mathrm{b}}^{\mathrm{OA}}}\right)\right]=0.381 \times(1-\mathrm{R}) /\right) /\left[(1-0.286) \times \frac{2.29}{2.52}\right)\right]=0.147$ 
where $\mathrm{SG}_{\mathrm{b}}^{\mathrm{RCA}}$ is the bulk specific gravity of $\mathrm{RCA}$ and $\mathrm{SG}_{\mathrm{b}}^{\mathrm{OA}}$ is the bulk specific gravity of $\mathrm{OA}$

3. Calculating volume of mortar in NAC and RAC:

Volume of mortar in NAC : $\mathrm{V}_{\mathrm{M}}^{\mathrm{NAC}}=1-\mathrm{V}_{\mathrm{NA}}^{\mathrm{NAC}}=1-0.381=0.619$

Volume of residual mortar in $\mathrm{RAC}: \mathrm{V}_{\mathrm{RM}}^{\mathrm{RAC}}=\mathrm{V}_{\mathrm{RCA}}^{\mathrm{RAC}} \times\left[1-(1-\mathrm{RMC}) \times \frac{\mathrm{SG}_{\mathrm{b}}^{\mathrm{RCA}}}{\mathrm{SG}_{\mathrm{b}}^{\mathrm{OA}}}\right]=0.147 \times\left[1-(1-0.286) \times \frac{2.29}{2.52}\right]=0.052$

Volume of new mortar in $\mathrm{RAC}: \mathrm{V}_{\mathrm{NM}}^{\mathrm{RAC}}=\mathrm{V}_{\mathrm{M}}^{\mathrm{NAC}}-\mathrm{V}_{\mathrm{RM}}^{\mathrm{RAC}}=0.617-0.052=0.567$

4. Calculating required weight of each material in RAC:

Oven - dry weight of RCA : $\mathrm{W}_{\mathrm{OD}-\mathrm{RCA}}^{\mathrm{RAC}}=\mathrm{V}_{\mathrm{RCA}}^{\mathrm{RAC}} \times \mathrm{SG}_{\mathrm{b}}^{\mathrm{RCA}} \times 1000=0.147 \times 2.29 \times 1000=336 \mathrm{~kg}$

Oven - dry weight of NA : $\mathrm{W}_{\mathrm{OD}-\mathrm{NA}}^{\mathrm{RAC}}=\mathrm{V}_{\mathrm{NA}}^{\mathrm{RAC}} \times \mathrm{SG}_{\mathrm{b}}^{\mathrm{NA}} \times 1000=0.286 \times 2.63 \times 1000=752 \mathrm{~kg}$

Oven - dry weight of FA : $\mathrm{W}_{\mathrm{OD}-\mathrm{FA}}^{\mathrm{RAC}}=\mathrm{W}_{\mathrm{OD}-\mathrm{FA}}^{\mathrm{NAC}} \times \frac{\mathrm{V}_{\mathrm{NM}}^{\mathrm{RAC}}}{\mathrm{V}_{\mathrm{M}}^{\mathrm{NAC}}}=720 \times \frac{0.567}{0.619}=660 \mathrm{~kg}$

Weight of water : $W_{\text {Water }}^{\mathrm{RAC}}=\mathrm{W}_{\text {Water }}^{\mathrm{NAC}} \times \frac{\mathrm{V}_{\mathrm{NM}}^{\mathrm{RAC}}}{\mathrm{V}_{\mathrm{M}}^{\mathrm{NAC}}}=175 \times \frac{0.567}{0.619}=160 \mathrm{~kg}$

Weight of cement : $\mathrm{W}_{\text {Cement }}^{\mathrm{RAC}}=\mathrm{W}_{\mathrm{Cement}}^{\mathrm{NAC}} \times \frac{\mathrm{V}_{\mathrm{NM}}^{\mathrm{RAC}}}{\mathrm{V}_{\mathrm{M}}^{\mathrm{NAC}}}=389 \times \frac{0.567}{0.619}=357 \mathrm{~kg}$

\section{References}

1. Kim, J. Construction and demolition waste management in Korea: Recycled aggregate and its application. Clean Technol. Environ. Policy 2021, 23, 2223-2234. [CrossRef]

2. Zhu, R.; Alam, S.Y.; Loukili, A. An experimental investigation on the correlation between the aggregate size effect and the structural size effect. Eng. Fract. Mech. 2020, 234, 107101. [CrossRef]

3. Mora, C.F.; Kwan, A.K.H. Sphericity, shape factor, and convexity measurement of coarse aggregate for concrete using digital image processing. Cem. Concr. Res. 2000, 30, 351-358. [CrossRef]

4. Grabiec, A.M.; Zawal, D.; Szulc, J. Influence of type and maximum aggregate size on some properties of high-strength concrete made of pozzolana cement in respect of binder and carbon dioxide intensity indexes. Constr. Build. Mater. 2015, 98, 17-24. [CrossRef]

5. Xu, G.; Shen, W.; Fang, D.; Zhou, M.; Zhang, B.; Du, X.; Zhang, D. Influence of size and surface condition of distributing-filling coarse aggregate on the properties of aggregate-interlocking concrete. Constr. Build. Mater. 2020, 261, 120002. [CrossRef]

6. Junak, J.; Sicakova, A. Effect of Surface Modifications of Recycled Concrete Aggregate on Concrete Properties. Buildings 2017, 8, 2. [CrossRef]

7. Wu, K.R.; Chen, B.; Yao, W.; Zhang, D. Effect of coarse aggregate type on mechanical properties of high-performance concrete. Cem. Concr. Res. 2001, 31, 1421-1425. [CrossRef]

8. Vu, X.H.; Daudeville, L.; Malecot, Y. Effect of coarse aggregate size and cement paste volume on concrete behavior under high triaxial compression loading. Constr. Build. Mater. 2011, 25, 3941-3949. [CrossRef]

9. Meddah, M.S.; Zitouni, S.; Belâabes, S. Effect of content and particle size distribution of coarse aggregate on the compressive strength of concrete. Constr. Build. Mater. 2010, 24, 505-512. [CrossRef]

10. Haque, M.B.; Tuhin, I.A.; Farid, M.S.S. Effect of aggregate size distribution on concrete compressive strength. SUST J. Sci. Technol. 2012, 19, 35-39.

11. Hossain, M.K.; Rashid, M.A.; Karim, M.R. Effect of cement content and size of coarse aggregate on the strength of brick aggregate concrete. DUET J. 2015, 2, 20-24.

12. Ghorbani, S.; Sharifi, S.; Ghorbani, S.; Tam, V.W.; de Brito, J.; Kurda, R. Effect of crushed concrete waste's maximum size as partial replacement of natural coarse aggregate on the mechanical and durability properties of concrete. Resour. Conserv. Recycl. 2019, 149, 664-673. [CrossRef]

13. Woode, A.; Amoah, D.K.; Aguba, I.A.; Ballow, P. The effect of maximum coarse aggregate size on the compressive strength of concrete produced in Ghana. Civ. Environ. Res. 2015, 7, 7-12.

14. Basheer, L.; Basheer, P.A.M.; Long, A.E. Influence of coarse aggregate on the permeation, durability and the microstructure characteristics of ordinary Portland cement concrete. Constr. Build. Mater. 2005, 19, 682-690. [CrossRef]

15. Ondova, M.; Sicakova, A. Evaluation of the Influence of Specific Surface Treatments of RBA on a Set of Properties of Concrete. Materials 2016, 9, 156. [CrossRef] [PubMed]

16. Rondi, L.; Bregoli, G.; Sorlini, S.; Cominoli, L.; Collivignarelli, C.; Plizzari, G. Concrete with EAF steel slag as aggregate: A comprehensive technical and environmental characterisation. Compos. Part B Eng. 2016, 90, 195-202. [CrossRef]

17. De Domenico, D.; Faleschini, F.; Pellegrino, C.; Ricciardi, G. Structural behavior of RC beams containing EAF slag as recycled aggregate: Numerical versus experimental results. Constr. Build. Mater. 2018, 171, 321-337. [CrossRef]

18. Yang, S.; Lee, H. Structural performance of reinforced RCA concrete beams made by a modified EMV method. Sustainability 2017, 9, 131. [CrossRef] 
19. Bai, G.; Zhu, C.; Liu, C.; Liu, B. An evaluation of the recycled aggregate characteristics and the recycled aggregate concrete mechanical properties. Constr. Build. Mater. 2020, 240, 117978. [CrossRef]

20. Hansen, T.C. Recycled aggregates and recycled aggregate concrete second state-of-the-art report developments 1945-1985. Mater. Struct. 1986, 19, 201-246. [CrossRef]

21. Hasaba, S.; Kawamura, M.; Toriik, K.; Takemoto, K. Drying shrinkage and durability of the concrete made of recycled concrete aggregate. Trans. Jpn. Concr. Inst. 1981, 3, 55-60.

22. Descarrega, A. Quality Improvement of the Recycled Aggregates through Surface Treatment 2011. Master's Thesis, Universitat Politècnica de Catalunya, Barcelona, Spain, 10 October 2011.

23. Padmini, A.K.; Ramamurthy, K.; Mathews, M.S. Influence of parent concrete on the properties of recycled aggregate concrete. Constr. Build. Mater. 2009, 23, 829-836. [CrossRef]

24. Xia, D.; Xie, S.; Fu, M.; Zhu, F. Effects of maximum particle size of coarse aggregates and steel fiber contents on the mechanical properties and impact resistance of recycled aggregate concrete. Adv. Struct. Eng. 2021, 24, 3085-3098. [CrossRef]

25. McGinnis, M.J.; Davis, M.; de la Rosa, A.; Weldon, B.D.; Kurama, Y.C. Strength and stiffness of concrete with recycled concrete aggregates. Constr. Build. Mater. 2017, 154, 258-269. [CrossRef]

26. Basheer, L.; Kropp, J.; Cleland, D.J. Assessment of the durability of concrete from its permeation properties: A review. Constr. Build. Mater. 2001, 15, 93-103. [CrossRef]

27. Kim, N.; Kim, J.; Yang, S. Mechanical strength properties of RCA concrete made by a modified EMV method. Sustainability 2016, 8, 924. [CrossRef]

28. Fathifazl, G.; Abbas, A.; Razaqpur, A.G.; Isgor, O.B.; Fournier, B.; Foo, S. New mixture proportioning method for concrete made with coarse recycled concrete aggregate. J. Mater. Civ. Eng. 2009, 21, 601-611. [CrossRef]

29. Fathifazl, G.; Ghani Razaqpur, A.; Burkan Isgor, O.; Abbas, A.; Fournier, B.; Foo, S. Creep and drying shrinkage characteristics of concrete produced with coarse recycled concrete aggregate. Cem. Concr. Compos. 2011, 33, 1026-1037. [CrossRef]

30. Yang, S.; Lee, H. Drying Shrinkage and Rapid Chloride Penetration Resistance of Recycled Aggregate Concretes Using Cement Paste Dissociation Agent. Materials 2021, 14, 1478. [CrossRef]

31. Kim, J. Properties of recycled aggregate concrete designed with equivalent mortar volume mix design. Constr. Build. Mater. 2021, 301, 124091. [CrossRef]

32. Duan, Z.H.; Poon, C.S. Properties of recycled aggregate concrete made with recycled aggregates with different amounts of old adhered mortars. Mater. Des. 2014, 58, 19-29. [CrossRef]

33. Gokce, A.; Nagataki, S.; Saeki, T.; Hisada, M. Freezing and thawing resistance of air-entrained concrete incorporating recycled coarse aggregate: The role of air content in demolished concrete. Cem. Concr. Res. 2004, 34, 799-806. [CrossRef]

34. Butler, L.J.; West, J.S.; Tighe, S.L. Towards the classification of recycled concrete aggregates: Influence of fundamental aggregate properties on recycled concrete performance. J. Sustain. Cem. Mater. 2014, 3, 140-163. [CrossRef]

35. Gholampour, A.; Ozbakkaloglu, T. Time-dependent and long-term mechanical properties of concretes incorporating different grades of coarse recycled concrete aggregates. Eng. Struct. 2018, 157, 224-234. [CrossRef]

36. KS L5201 Portland Cement; Korean Agency Technol: Seoul, Korea, 2016.

37. KS F2503 Testing Method for Density and Absorption of Coarse Aggregate; Korean Agency Technol: Seoul, Korea, 2019.

38. Abbas, A.; Fathifazl, G.; Burkan Isgor, O.; Razaqpur, A.G.; Fournier, B.; Foo, S. Proposed method for determining the residual mortar content of recycled concrete aggregates. J. ASTM Int. 2008, 5, 12. [CrossRef]

39. De Juan, M.S.; Gutiérrez, P.A. Study on the influence of attached mortar content on the properties of recycled concrete aggregate. Constr. Build. Mater. 2009, 23, 872-877. [CrossRef]

40. Djerbi Tegguer, A. Determining the water absorption of recycled aggregates utilizing hydrostatic weighing approach. Constr. Build. Mater. 2012, 27, 112-116. [CrossRef]

41. KS F2502 Standard Test Method for Sieve Analysis of Fine and Coarse Aggregates; Korean Agency Technol: Seoul, Korea, 2019.

42. Tam, V.W.Y.; Tam, C.M.; Le, K.N. Removal of cement mortar remains from recycled aggregate using pre-soaking approaches. Resour. Conserv. Recycl. 2007, 50, 82-101. [CrossRef]

43. Fathifazl, G. Structural Performance of Steel Reinforced Recycled Concrete Members 2008. Ph.D. Thesis, Carleton University, Ottawa, ON, Canada, January 2018.

44. Brand, A.S.; Roesler, J.R.; Salas, A. Initial moisture and mixing effects on higher quality recycled coarse aggregate concrete. Constr. Build. Mater. 2015, 79, 83-89. [CrossRef]

45. Mefteh, H.; Kebaïli, O.; Oucief, H.; Berredjem, L.; Arabi, N. Influence of moisture conditioning of recycled aggregates on the properties of fresh and hardened concrete. J. Clean. Prod. 2013, 54, 282-288. [CrossRef]

46. Poon, C.S.; Shui, Z.H.; Lam, L.; Fok, H.; Kou, S.C. Influence of moisture states of natural and recycled aggregates on the slump and compressive strength of concrete. Cem. Concr. Res. 2004, 34, 31-36. [CrossRef]

47. KS F2402 Standard Test Method for Concrete Slump; Korean Agency Technol: Seoul, Korea, 2017.

48. KS F2421 Standard Test Method for Air Content of Fresh Concrete by the Pressure; Korean Agency Technol: Seoul, Korea, 2021.

49. KS F2405 Standard Test Method for Compressive Strength of Concrete; Korean Agency Technol: Seoul, Korea, 2017.

50. KS F2438 Standard Test Method for Static Modulus of Elasticity and Poisson's Ratio in Compression of Cylindrical Concrete Specimens; Korean Agency Technol: Seoul, Korea, 2017.

51. KS F2423 Standard Test Method for Tensile Splitting Strength of Concrete; Korean Agency Technol: Seoul, Korea, 2016. 
52. Alqarni, A.S.; Abbas, H.; Al-Shwikh, K.M.; Al-Salloum, Y.A. Treatment of recycled concrete aggregate to enhance concrete performance. Constr. Build. Mater. 2021, 307, 124960. [CrossRef]

53. Mi, R.; Pan, G.; Liew, K.M.; Kuang, T. Utilizing recycled aggregate concrete in sustainable construction for a required compressive strength ratio. J. Clean. Prod. 2020, 276, 124249. [CrossRef]

54. KS F4009 Ready-Mixed Concrete; Korean Agency Technol: Seoul, Korea, 2021.

55. Kou, S.C.; Poon, C.S. Effect of the quality of parent concrete on the properties of high performance recycled aggregate concrete. Constr. Build. Mater. 2015, 77, 501-508. [CrossRef]

56. Yang, S.; Lee, H. Mechanical properties of recycled aggregate concrete proportioned with modified equivalent mortar volume method for paving applications. Constr. Build. Mater. 2017, 136, 9-17. [CrossRef]

57. Dilbas, H.; Güneş, M.Ş. Mineral Addition and Mixing Methods Effect on Recycled Aggregate Concrete. Materials 2021, 14, 907. [CrossRef]

58. Dilbas, H.; Şimşek, M.; Çakir, Ö. An investigation on mechanical and physical properties of recycled aggregate concrete (RAC) with and without silica fume. Constr. Build. Mater. 2014, 61, 50-59. [CrossRef]

59. Yang, C.C. Effect of the Transition Zone on the Elastic Moduli of Mortar. Cem. Concr. Res. 1998, 28, 727-736. [CrossRef]

60. Sadati, S.; Khayat, K.H. Field performance of concrete pavement incorporating recycled concrete aggregate. Constr. Build. Mater. 2016, 126, 691-700. [CrossRef]

61. Etxeberria, M.; Vázquez, E.; Marí, A.; Barra, M. Influence of amount of recycled coarse aggregates and production process on properties of recycled aggregate concrete. Cem. Concr. Res. 2007, 37, 735-742. [CrossRef]

62. Wagih, A.M.; El-Karmoty, H.Z.; Ebid, M.; Okba, S.H. Recycled construction and demolition concrete waste as aggregate for structural concrete. HBRC J. 2013, 9, 193-200. [CrossRef] 